\title{
Dynamics of faecal egg count in natural infection of Haemonchus spp. in Indian goats
}

\author{
Nimisha Agrawal ${ }^{1}$, Dinesh Kumar Sharma ${ }^{1}$, Ajoy Mandal ${ }^{2}$, Pramod Kumar Rout ${ }^{1}$ and Yogendra Kumar Kushwah
}

1. Division of Goat Health and Goat Genetics and Breeding, Central Institute for Research on Goats, Mathura, Uttar Pradesh, India; 2. Animal Breeding Section, Eastern Regional Station, National Dairy Research Institute, Nadia, West Bengal, India.

Corresponding author: Dinesh Kumar Sharma, email: Ikofwb@yahoo.co.in, NA: agrawalnimisha06@gmail.com, AM: ajoymandal@gmail.com, PKR: pramod@gmail.com, YKK: yogendrakushwah786@gmail.com

Received: 04-10-2014, Revised: 04-12-2014, Accepted: 11-12-2014, Published online: 09-01-2015

doi: 10.14202/vetworld.2015.38-41 How to cite this article: Agrawal N, Sharma DK, Mandal A, Rout PK, Kushwah YK (2015) Dynamics of faecal egg count in natural infection of Haemonchus Spp. in Indian goats, Veterinary World, 8(1): 38-41.

\begin{abstract}
Aim: Dynamics of faecal egg count (FEC) in Haemonchus spp. infected goats of two Indian goat breeds, Jamunapari and Sirohi, in natural conditions was studied and effects of genetic and non-genetic factors were determined.

Materials and Methods: A total of 1399 faecal samples of goats of Jamunapari and Sirohi breeds, maintained at CIRG, Makhdoom, Mathura, India and naturally infected with Haemonchus spp., were processed and FEC was performed. Raw data generated on FEC were transformed by $\log _{\mathrm{e}}(\mathrm{FEC}+100)$ and transformed data (least squares mean of FEC [LFEC]) were analyzed using a mixed model least squares analysis for fitting constant. Fixed effects such as breed, physiological status, season and year of sampling and breed $\times$ physiological states interaction were used.

Result: The incidence of Haemomchus spp. infection in Jamunapari and Sirohi does was 63.01 and $47.06 \%$, respectively. The mean LFEC of both Jamunapari and Sirohi (does) at different physiological stages, namely dry, early pregnant, late pregnant early lactating and late lactating stages were compared. Breed, season and year of sampling had a significant effect on FEC in Haemomchus spp. infection. Effect of breed $\times$ physiological interaction was also significant. The late pregnant does of both breeds had higher FEC when compared to does in other stages.
\end{abstract}

Conclusion: Breed difference in FEC was more pronounced at the time of post kidding (early lactation) when sharp change in FEC was observed.

Keywords: faecal egg count, goats, Haemonchus.

\section{Introduction}

Faecal egg count (FEC) in gastrointestinal nematode infection represents the severity of disease as well as the immune status of the animal. However, dynamics of FEC varies in different seasons, physiological states, breeds, age, and managements and also in different geographic area [1]. Relaxation of immunity in reproducing females also affects FEC that results in peri-parturient period. The peri-parturient rise (PPR) in FEC is important because it increases pasture contamination at the time of parturition that in turn greatly increases the risk of infection in the very susceptible young ones. The marked increase in susceptibility of lactating animals to gastrointestinal (GI) nematode infection had been extensively documented in sheep; however, it lack evidences in goats. PPR in FEC has been reported in lactating Galla does and Small East African goats breed in Kenya [2], dairy goats in The Netherland [3], indigenous goats in Brazil [4]. The stress of high level of milk production was associated with increased susceptibility in alpine dairy goats to GI nematode in France [5]. Some resistant sheep breeds like St.

Copyright: The authors. This article is an open access article licensed under the terms of the Creative Commons Attributin License (http:// creative commons.org/licenses/by/2.0) which permits unrestricted use, distribution and reproduction in any medium, provided the work is properly cited.
Croix and Florida Native certainly had a lower PPR than temperate breeds like Rambouillet or dorset $x$ Rambouillet [6].

Reports on dynamics of FEC, especially during peri-parturient period and other physiological states in Indian sheep and goat breeds are meager [7-10]. Therefore, the objective of the present study was the dynamics of FEC in two goat breeds in natural infection of Haemomchus spp. in different physiological states under semi-intensive management system.

\section{Material and Methods}

\section{Ethical approval}

All essential procedures of sample collections were performed strictly as specified by Institutional Ethics Committee with minimal stress to animals.

\section{Location of study}

The study was conducted at the Central Institute for Research on Goats (CIRG), Makhdoom, Farah, Mathura, Uttar Pradesh, India, located at $27^{\circ} 29^{\prime}$ North latitude and $77^{\circ} 40^{\prime}$ East latitude (msl-174 m). The climate of the study area is classified as tropical (semiarid zone). Temperature varies from $21^{\circ} \mathrm{C}$ to $42^{\circ} \mathrm{C}$ in summer and $6^{\circ} \mathrm{C}$ to $30^{\circ} \mathrm{C}$ in winter (both average). The annual rainfall is about $750 \mathrm{~mm}$ and scattered mainly during June-September. Winter is generally dry and cold. The soil is sandy, and vegetation is composed of natural pasture and bushes. 


\section{Flock description and management}

Jamunapari and Sirohi does in different physiological states viz. pregnant, lactating and dry maintained at Central Institute for Research on Goats, Makhdoom, Mathura (India) were used for the study. In brief, Jamunapari is a large sized goat known for its milk production [11]. It is native of Chakarnagar area of Etawah district of Uttar Pradesh, India. The average daily milk production varies from 1 to $2.5 \mathrm{~L}$. Average lactation length was of $151.42 \pm 10.92$ days. The Sirohi, one of the important defined breeds of India, is native of Rajasthan. The lactation length averaged as 167.5 days under semi-intensive system [12]. Being breeding flocks, animals of both flocks were bred as per breeding schedule. Two breeding seasons were planned every year resulting two pregnancy periods of 5 months each i.e. May-October and OctoberMarch. As per farm schedule, the animals of all categories were maintained separately in semi-intensive system of management. They were provided concentrate ration with mineral mixture i.e. $400 \mathrm{~g} / \mathrm{animal} / \mathrm{day}$ for pregnant and lactating animals and $150 \mathrm{~g} / \mathrm{animal} /$ day for dry animal. All three categories were allowed $6 \mathrm{~h}$ grazing daily. De-worming was carried out twice annually i.e. in the pre-monsoon (June-July) and the post-monsoon (September-October) seasons. Faecal samples for parasitological examination were collected either before the anthelmintic treatment or after an interval of 4-weeks post-treatment.

\section{Parasitological procedure}

The faecal samples were collected from the rectum of animals of both breeds, and FEC was conducted using a modified McMaster Technique [13] with each egg counted representing $200 \mathrm{eggs} / \mathrm{g}$ of faeces. Pooled faecal samples randomly collected from $5 \%$ animals (3 times) in rainy seasons were cultured for larvae to define the species composition of the nematode infecting the flocks.

\section{Data and experimental design}

The study was conducted from August 2006 to June 2008. For study, a total of 1399 samples, 838 from Jamunapari and 561 from Sirohi, were collected and examined. The collected samples were grouped on the basis of physiological status of donor viz. dry (non-pregnant, non-lactating), pregnant and lactating. Samples from pregnant does were subdivided into early (in $4^{\text {th }}$ month of gestation) and late (15-30 days before kidding) pregnant stages. Similarly, faecal samples from lactating does were also divided into early ( $1^{\text {st }}$ month) and late ( $3^{\text {rd }}$ month) lactation to study the variation in FEC more discreetly. Thus, FEC of adult females was monitored at five different stages such as dry, early pregnant, late pregnant, early lactating and late lactating periods. Faecal samples collection was, however, either before the anthelmintic treatment or 4-weeks post-treatment.

Similarly, observations of FEC were also analyzed on seasons (summer, rainy, winter) basis.

\section{Statistical analysis}

Data generated on FEC was Log-transformed $\left(\log _{\mathrm{e}}[\mathrm{FEC}+100]\right)$ to normalize. Normalized data were analyzed statistically through least squares analysis [14]. The statistical models applied included only fixed effects, and effects fitted varied with sampling periods. The fixed effects were Breed ( 2 classes), physiological states of goats (5 classes: dry, early pregnant, late pregnant, early lactating and late lactating), seasons ( 3 classes), year ( 3 classes). The dependent variables analyzed were FEC.

To determine the effects of various factors on FEC in different physiological stages following model was used:

$$
\begin{aligned}
& \mathrm{Z}_{\mathrm{ijklm}}=\mu+\mathrm{B}_{\mathrm{i}}+\mathrm{P}_{\mathrm{j}}+\mathrm{S}_{\mathrm{k}}+\mathrm{Y}_{1}+\left[\mathrm{B} \times \mathrm{P}_{\mathrm{ij}}+\mathrm{e}_{\mathrm{ijk}}\right. \\
& \text { Where, } \\
& \mathrm{Z}_{\mathrm{ijlm}}=\text { is the } \mathrm{m}^{\text {th }} \text { observation of individu- }
\end{aligned}
$$
als, $\mu=$ Overall mean, $B_{i}=$ Fixed effect of $i^{\text {th }}$ breed $[i=1,2], P_{j}=$ Fixed effect of $j^{\text {th }}$ physiological conditions $[j=1,2, \ldots .5], S_{k}=$ Fixed effect of $k^{\text {th }}$ season of sampling $[\mathrm{k}=1,2,3], \mathrm{Y}_{1}=$ Fixed effect of $\mathrm{t}^{\text {th }}$ year of sampling $[1=1,2,3],[\mathrm{B} \times \mathrm{P}]_{\mathrm{ij}}$ = Interaction effect between $\mathrm{i}^{\text {th }}$ breed and $\mathrm{j}^{\text {th }}$ physiological condition, $\mathrm{e}_{\mathrm{ij}}=$ Random error associated with observation with mean 0 [zero] and variance $\delta^{2}$ e.

The mean values resulted from the analysis were reverse transformed and presented in modified mean as geometric means of FEC (GFEC). The comparison of different sub-groups means was made by Duncan's multiple range test as described by Kramer [15].

\section{Results and Discussion}

In this climatic zone, the major source of parasitic infection in animals was from pasture. The morphological differentiation of larvae, emerged out from bulk cultures for each sampling from both the breeds, showed that the predominant larvae were of Haemonchus contortus. Other GI nematodes like Oesophagostomum spp. (1.66\%), Strongyloides spp. $(2.00 \%)$ and Trichuris spp. (1.33\%) were also recorded, however, they were sporadically occurring. Previous reports from this area also describe Haemonchus spp. as the predominant strongyle infection in semi-arid zone of India [9,16,17]. The overall prevalence rate of Haemonchus spp. infection in the flocks under the study was $63.01 \%$ (i.e. $528 / 838$ ) for Jamunapari and $47.06 \%$ (i.e. 264/561) for Sirohi does.

The moderate incidence of parasitism observed in the present study was similar as has been reported from semi-arid region of India [18] and some other part of the world [19].

Least squares mean of FEC (LFEC) and back transformed values of GFEC in different physiological stages of both breeds are shown in Table-1. In the present study, breeds had significant $(\mathrm{p}<0.01)$ effect on FEC and Sirohi does have significantly lower FEC values than Jamunapari does. The effect of physiological state of animal on FEC was also statistically significant. Though, FEC in dry does and early pregnant 
Table-1: Overall LSM of faecal egg counts in Jamunapari and Sirohi goats in different physiological stages*.

\begin{tabular}{|c|c|c|}
\hline Source of variation & No. & $\begin{array}{l}\text { LFEC (GFEC/ } \\
\text { g of faeces) }\end{array}$ \\
\hline $\begin{array}{l}\text { Overall mean of animals } \\
\text { Breed }\end{array}$ & 1399 & $6.14 \pm 0.05(364)$ \\
\hline Jamunapari & 838 & $6.30 \pm 0.05^{\mathrm{a}}(444)$ \\
\hline $\begin{array}{l}\text { Sirohi } \\
\text { Phvsiological stages }\end{array}$ & 561 & $5.97 \pm 0.07^{b}(291)$ \\
\hline Dry & 731 & $6.00 \pm 0.05^{\mathrm{a}}(303)$ \\
\hline Early pregnant & 122 & $5.99 \pm 0.13^{\text {a }}(299)$ \\
\hline Late pregnant & 194 & $6.41 \pm 0.10^{\mathrm{b}}(507)$ \\
\hline Early lactation & 170 & $6.17 \pm 0.12^{\mathrm{ab}}(378)$ \\
\hline Late lactation & 182 & $6.10 \pm 0.10^{\mathrm{a}}(345)$ \\
\hline \multicolumn{3}{|l|}{ Season of collection } \\
\hline Summer & 452 & $6.16 \pm 0.08^{\mathrm{a}}(373)$ \\
\hline Rainy & 413 & $6.70 \pm 0.08^{b}(712)$ \\
\hline Winter & 534 & $5.54 \pm 0.07^{c}(154)$ \\
\hline \multicolumn{3}{|l|}{ Year of collection } \\
\hline 2006 & 432 & $5.71 \pm 0.07^{\mathrm{a}}(201)$ \\
\hline 2007 & 657 & $6.08 \pm 0.06^{b}(337)$ \\
\hline 2008 & 310 & $6.62 \pm 0.09^{c}(649)$ \\
\hline \multicolumn{3}{|l|}{ Breed $\times$ physiological states } \\
\hline Jamunaparixdry & 401 & $6.17 \pm 0.06^{\mathrm{a}}(378)$ \\
\hline Jamunapari×Early pregnant & 78 & $6.32 \pm 0.15^{\mathrm{a}}(455)$ \\
\hline Jamunaparixlate pregnant & 122 & $6.44 \pm 0.12^{\mathrm{a}}(526)$ \\
\hline Jamunaparixearly lactation & 133 & $6.34 \pm 0.13 \mathrm{a}[466]$ \\
\hline Jamunapari×late lactation & 104 & $6.21 \pm 0.11^{\mathrm{a}}(397)$ \\
\hline Sirohixdry & 330 & $5.83 \pm 0.07^{\mathrm{a}}(240)$ \\
\hline Sirohixearly pregnant & 44 & $5.66 \pm 0.20^{\mathrm{a}}(187)$ \\
\hline Sirohixlate pregnant & 72 & $6.39 \pm 0.16^{b}(495)$ \\
\hline Sirohixearly lactation & 37 & $6.00 \pm 0.22^{\mathrm{ab}}(303)$ \\
\hline Sirohixlate location & 78 & $5.99 \pm 0.16^{\mathrm{ab}}(299$ \\
\hline
\end{tabular}

*Means with different superscripts in column under a source of variation differ significantly from each other. LFEC=Least squares mean of faecal egg count, GFEC=Geometric means faecal egg count, LSM=Least mean square

could not show significant difference, the mean LFEC of late pregnant does was significantly higher than the corresponding values in dry does $(\mathrm{p}<0.05)$ (Table-1). Subsequently LFEC started receding till late lactation stage and further to maintain its dry period state in both breeds. The breed $\times$ physiological status interaction was significant $(\mathrm{p}<0.05)$ for FEC. There was a different pattern of the peri-parturient change in two breeds. In Jamunapari goats, there was no significant change observed in FEC among pregnant, dry, and lactating goats. Our findings corroborated with the findings of Chauhan et al. [8] who reported no significant difference between dry, pregnant, and lactating does of the same breed. In Sirohi, up to early pregnant stage change in mean LFEC was not significant. However, mean LFEC in late pregnant and early lactating Sirohi was significantly higher $(\mathrm{p}<0.05)$ than dry and early pregnant animals [19]. No significant change in FEC between late pregnant and lactating Sirohi does was same as in Jakhrana, a native goat breed of semi-arid Rajasthan [9]. In Sirohi, changes in FEC were more apparent than in Jamunapari. Both breeds showed highest LFEC in late pregnancy similar to Gibbs and Barger [20] who found peak egg counts just before lambing. However, after kidding there was a decline in FEC (Figure-1). Reduction in FEC from late pregnant

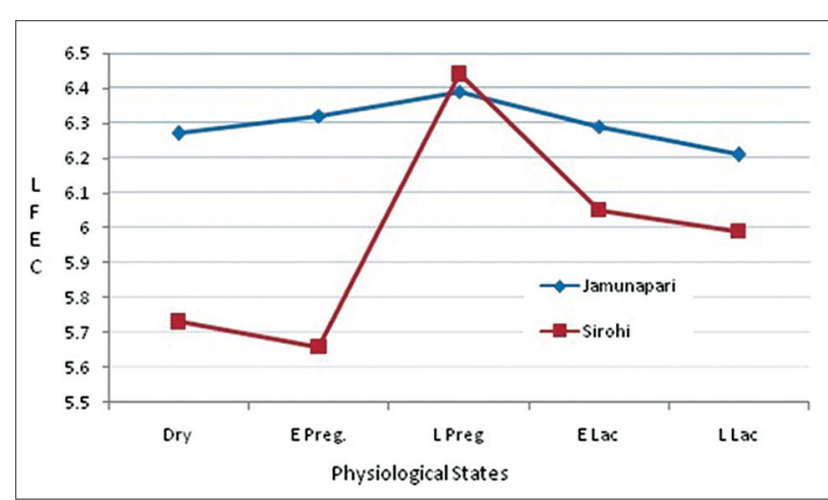

Figure-1: Peri-parturient rise (faecal egg count) in Jamunapari and Sirohi Does.

to early lactation stage might be due to farm management practices, where the pre-kidding de-worming was necessary. However, this reduction was less apparent in Jamunapari goats may be attributed to their higher milk production as compared to Sirohi does (Figure-1). Hoste and Chartier [5] stated that the stress of high level of milk production in Alpine dairy goats (France) was associated with increased susceptibility of GI nematodes. Similarly, Baker et al. [2] reported more marked and persistent PPR in FEC in Galla (high milk producing breed) than SEA goats. Also, there is report that systemic immunity began to wane during late pregnancy [21]. The difference in mean LFEC can be attributed to the difference in grazing habit or breed difference.

Effect of season of collection on FEC was significant $(\mathrm{p}<0.01)$. The highest mean LFEC was found in the rainy season, followed by summer and winter season, for both Jamunapari and Sirohi goats. These findings were in accordance with previous reports $[9,16,18,19]$ which described maximum EPG in monsoon. However, the results were contrary to Fakae [22] who recorded incidence as high 77.8-100\% with no definite seasonal distinction. The year of sampling had significant $(p<0.05)$ effect on LFEC. This may be attributed to change in management, selection of sires and environmental conditions such as ambient temperature, humidity, rainfall, etc. Furthermore, there were reports that described the gradual increase in FECs over the gestation period, which peaked during lactation during winter and spring lambing season [23].

\section{Conclusion}

The study revealed breed had a significant effect on FEC and so also the physiological status. PPR was sharper in Sirohi goats. In the present study, prevalence and intensity of infection was significantly higher in Jamunapari goats as compared to Sirohi.

\section{Author's Contributions}

NA, DKS designed the work plan, collected and processed the faecal samples for FECs. YKK and AM compiled, tabulated, transformed and analyzed the 
data. AM and PKR interpreted the result. DKS, AM and PKR prepared the manuscript. All authors read and approved the final manuscript.

\section{Acknowledgments}

The authors are thankful to Director of the Institute for providing all facilities and financial support to carry out the study. The helps rendered by the staffs of Jamunapari and Sirohi units are also duly acknowledged.

\section{Competing Interests} interests.

The authors declare that they have no competing

\section{References}

1. Ahmad, L.B., Chisti, M.Z, Fayaz, A. and Hidayatullah, T. (2012) A survey of gastrointestinal helminth parasites of slaughtered sheep and goats in Ganderbal, Kashmir. Glob. Vet., 8(4): 338-341.

2. Baker, R.L., Mwamach, D.M., Audho, J.O., Aduda, E.O. and Thorpe, W. (1998) Resistance of Galla and Small East African goats in the sub humid tropics to gastrointestinal nematode infections and the peri-parturient rise in the faecal egg counts. Vet. Parasitol., 79(1): 53-64.

3. Jansen, J. (1982) Observations on the spring rise faecal strongyle egg counts in goats. Tijdschr. Diergeneeskd., 107(5): 186-189.

4. Costa, C.A.F. (1983) Increase of gastro-intestinal nematode egg counts in lactating goat. Pesqui Agropecu Bras. Ser. Vet., 18: 919-922.

5. Hoste, H. and Chartier, C. (1993) Comparison of the effects on milk production of concurrent infection with Haemonchus contortus and T. colubriformis in high and low producing dairy goats. Am. J. Vet. Res., 54(1): 1886-1893.

6. Zajac, A.M., Herd, R.P. and McClure, K.E. (1988) Trichostrongylid parasite populations in pregnant or lactating and unmated Florida native and dorset rambouilet ewes. Int. J. Parasitol., 18: 981-985.

7. Yadav, N.K., Mandal, A., Sharma, D.K., Rout, P.K. and Roy, R. (2008) Influence of reproductive stages on gastrointestinal nematodes of sheep. Indian J. Anim. Sci., 78(2): 161-162.

8. Chauhan, K.K., Rout, P.K., Singh, P.K., Mandal, A., Singh, S.K. and Roy, R. (2003) Genetic resistance of Barbari and Jamunapuri Kids to natural infection with gastrointestinal nematodes. Trop. Anim. Health Prod., 35: 397-408.

9. Agrawal, N., Sharma, D.K. and Mandal, A. (2010) Faecal egg output in Jakhrana goats naturally infected by Haemonchus contortus: Physiological states and seasons effect. Indian J. Anim. Sci., 80: 509-511.
10. Mandal, A., Agrawal, N., Nigam, P., Sharma, D. K. and Roy, R. (2011) Susceptibility of Haemonchus contortus infection in Jakhrana goats. Indian J. Anim. Sci., 81(2): 149-151.

11. Rout, P.K., Saxena, V.K., Khan, B.U., Mandal, A.K., Roy, R. and Singh, S.K. (2000) Characterization of Jamunapari goats in their home tract. Anim. Gen. Resour. Inf., 28: 32-43.

12. Singh, D. (2005) Factors affecting lactation traits in Sirohi goats maintained under Semi-intensive system. Proceedings of VIII National Conference on Animal Genetics and Breeding, 8-10 March, 2005. p58.

13. MAFF [Ministry of Agriculture, Fisheries and Food]. (1977) Manual of Veterinary Parasitological Techniques. Technical Bulletin No. 18. Her Majesty's Stationery Officer, London. p129.

14. Harvey, W.R. (1990) Users Guide for the LSMLMW PC-2 Version Mixed Model Least Squares Maximum Likelihood Computer Program Minneograph. Columbus, Ohio, USA.

15. Kramer, C.Y. (1957) Extension of multiple range tests to group correlated adjusted means. Biometrics, 13: 13.

16. Sharma, D.K., Agrawal, N., Mandal, A., Nigam, P. and Bhushan, S. (2009) Coccidia and gastrointestinal nematode infections in semi-intensively managed Jakhrana goats of semi-arid region of India. Trop. Subtrop. Agroecosystem, 11: 135-139.

17. Shimelis, D., Asmare, A. and Wudu, T. (2011) Epidemiology of gastrointestinal helminthiasis of small ruminants in selected sites of North Gondar zone, Northwest Ethiopia. Ethiop. Vet. J., 15(2): 57-68.

18. Garg, G., Sharma, D.K., Agrawal, R.D. and Rout, P.K. (2003) Epidemiology of Haemonchus contortus infection in goats in semi-arid region of India. J. Vet. Parasitol., 17(1): 57-60.

19. Schoenian, S. (2012) Periparturient Egg Rise-American Consortium for Small Ruminant Parasite Control. Available from: http://www.acsrpc.org/Resources/Topics/PPER.html. Last accessed on 25-11-2014.

20. Gibbs, H.C. and Barger, I.A. (1986) Haemonchus contortus and other trichostrongylid infections in parturient, lactating and dry ewes. Vet. Parasitol., 22(1-2): 57-66.

21. Beasley, A.M., Kahn, L.P. and Windon, R.G. (2012) The influence of reproductive physiology and nutrient supply on the peri-parturient relaxation of immunity to the gastrointestinal nematode Trichostrongylus colubriformis in Merino ewes. Vet. Parasitol., 188(3-4): 306-324.

22. Fakae, B.B. (1990) Seasonal changes and hypobiosis in $H$. contortus infection in the West-African Dwarf sheep and goats in the Nigerian derived Savana. Vet. Parasitol., 36(1-2): 123-130.

23. Falzon, L.C., Menzies, P.I., Shakya, K.P., Jones-Bitton, A., Vanleeuwen, J., Avula, J., Jansen, J.T. and Peregrine, A.S. (2013) A longitudinal study on the effect of lambing season on the periparturient egg rise in Ontario sheep flocks. Prev. Vet. Med., 110(3-4): 467-480. 